\title{
Analysis of 3D Body Scanning for Body Measurement Extraction Considering the Cultural Context
}

\author{
Arzu VURUSKAN ${ }^{\star a, b}$, Ender BULGUN ${ }^{b}$ \\ ${ }^{a}$ Department of Fashion Design, Izmir University of Economics, Izmir, Turkey \\ ${ }^{b}$ Department of Textile Engineering, Dokuz Eylül University, Izmir, Turkey
}

\begin{abstract}
Besides developing new technologies, it is rather important to understand the consumer background in order to adapt new developments. Identifying consumer interest and willingness for 3D body scanning in apparel and fashion industry is crucial for the integration of scanning technology to a national size survey or customization activities. The aim of this research was to identify consumer interest and awareness or consumer reactions to body scanning considering the cultural context. Consumer opinions were first discussed by analyzing a sample group in Turkey. Two groups were created; first with the students and second with the academics. No age or gender limit was identified for this part of the survey. Consequently, another test group was created with male students for measurement extraction with body scanning, and a following questionnaire aimed to examine their reactions to the process after actually being body scanned.
\end{abstract}

Last part of the survey was intended for female participants. Two groups of sample sets were created for measurement taking. Participants in the first group were chosen from a German university and were measured by scanning; whereas the second group consisted of participants from Turkish universities and were measured by traditional anthropometric tools. Questions and observations aimed to identify the awareness of body scanning as well as the comfort level during measurement taking process.

The survey for examining consumer awareness and interest for scanning was realized as a part within a project, where the body scanning technology is analyzed with the aim of integrating this technology into a national size survey or apparel customization purposes. Turkey as a production country needs more customized solutions and technological investments for the maintenance and development of apparel and fashion industry. Besides this, a national size survey would carry importance considering the increasing population and consumer potential of the country. This study was important as a market survey; however, the limited number of participants was a limitation in the study. An extended survey would create more benefit to proceed further for possible applications such as a national size survey or made-to-measure developments.

Keywords: Consumer reactions, 3D body scanning, national size survey

\section{Introduction}

Body scanning is a new technology started to develop since the end of the last century. The main applications of body scanning in clothing industry is non-contact body measurements for size surveys, pattern generation for customization, producing a tailor made mannequin for a target market and clothing fit evaluation of appearance, such as drape and wrinkling [1].

Being a relatively new technology, use of body scanners in apparel and fashion industry is limited and still needs further development. Besides the technological development on body scanning, the success of research or commercial activities related with scanning is dependent on consumer acceptance. Therefore, one of the research directions about body scanning goes through exploring consumer behavior. Studies conducted in this research field are mainly based on some statistical data trying to evaluate consumer profile and consumer interest, mostly in conjunction with mass customization. Loker, et al. (2004) took attention to the female consumers' reactions to body scanning by conducting a study of scanning female subjects [2]. Within this research, two related studies were conducted. First, 203 female participants aged 35 to 55 were surveyed after they were scanned and viewed their scanned images on the computer monitor and in a movie file. General acceptance of scanning was very high. However, women who were married and had over $\$ 100,000$ household income were significantly less comfortable with some aspects of the body scan process. At the end of the study, it was claimed that some participants were unsettled and unprepared for interactions with body scanning technology. Lee, et al. (2002) investigated merchandising issues associated with 
apparel mass customization to explore the preferences for product, process, and the place affecting the success of apparel mass customization [3]. Within this study, body scanning process was also evaluated. It was found that during the body scanning process female subjects preferred most likely to wear their underwear or street clothes and get help from trained sales persons. The longest amount of time they preferred to spend for the body scanning process was six to ten minutes. Female subjects claimed that they would prefer the body measurement information to be stored in a central database to be used by any company creating garments for them. Fiore, et al. (2001) examined whether an individual's preferred level for environmental stimulation, which was defined as optimum stimulation level (OSL) was associated with the types of products, services and experiences desired from mass customization of apparel. Within this research authors also hypothesized if OSL had significant positive correlations with body scanning and found out that OSL didn't have significant correlations with the more banal willingness to use body scanning services for better fitting products or overall commitment to using body scanning [4]. In another research, Loker, et al. (2004) analyzed the consumer interest in commercial application of body scan data by surveying a sample of 203 women 34-55 years of age about their interest in scanning. Body scan technology in apparel industry was defined as being targeted for automated custom fit, size and fit prediction, virtual try-on, personal shopper services, co-design mass customization, custom pattern development for home sewers and research. After being scanned, participants' interest in these six commercial applications was evaluated. Results of the study suggested a great interest and consequently consumer potential for body scan applications [5].

Research regarding the consumer reactions to scanning should be realized considering local conditions within the cultural context, since consumer behavior is much related with such factors. Analyzing the case of Turkey as an important clothing production site, Turkey seems to be losing its competitive advantage in comparison with other production countries like China, India or Bangladesh. According to some figures on clothing imports to the EU over the period 2004-2008, China made a big step with annual growth rate of $21 \%$ over that time. However, Turkey, as the closest rival supplier has barely seen any change in its EU exports over this period (0.5\%), while Bangladesh and India, the next most important sources, have also seen increases [6]. Under these conditions, Turkey as a production country needs more customized solutions, technological investments and research for the maintenance and development of apparel and fashion industry. 3D body scanner technology, as a state-of-the-art issue, is one of the research fields for technological developments. Considering that the research and commercial use of 3D body scanning technology is very limited in Turkey, this study aimed to identify consumer interest and reactions to body scanning process as well as creating awareness on this technology.

The use of 3D body scanners in clothing is mostly linked with the apparel customization purposes. The success of customization process is tied directly to the availability of an accurate set of body measurements, which can be obtained with body scanners. However, 3D body scanners are also important in anthropometric size surveys with reducing the time of measuring and reducing the use of labor. Anthropometric surveys are necessary to develop a standard sizing system for better fitting clothes. Attempts to prepare size charts for Turkish population started at 1970s. In Turkey, the earliest anthropometric studies were conducted in the army in 1978 so that better fitting uniforms could be produced for the soldiers. Following this, some other approaches were realized with women and with girls between the age of 7-11, 12-17 and 18-22. However, all these approaches were limited within specific regions of Turkey and were not representing the whole population [7,8]. Production companies in Turkey tend to produce either their own sizes charts or adapt another country's chart based on their target group. Since there is not such anthropometric data for the Turkish population, consumers face fitting problems with ready-to-wear. A recent survey was conducted in Turkey to understand the fitting problems of Turkish women and customer satisfaction [9]. Sample group for the survey consisted of 589 Turkish women between ages 25 and 55 . It was observed the size number of $73 \%$ changed from one brand to the other and $90.8 \%$ of participants had fitting problem with the garments they bought.

A national size survey conducted with a body scanner in Turkey would be important to reduce fitting problems in ready-to-wear as well as leading to further developments for customization and body scanner integrated activities. Therefore, identifying the consumer interest in scanning carries importance to broaden research directions. 
In this study, based on the main objective of understanding the consumer tendency to scanning, process details such as identifying the preferences for measurement taking or understanding the comfort level during scanning were defined as specific purposes.

\section{Method}

The surveys regarding the consumer approach for scanning was developed within a part of a research project on apparel customization. Sample groups were created within various phases of the project. Research on scanning consisted of three sections to evaluate consumer tendency.

\subsection{Forming the first sample group to understand consumer tendencies}

The first section included the survey aiming to examine Turkish consumers' acceptance and understanding to apparel mass customization and body scanning. Thinking that the customization and the 3D scanner is a new concept in Turkey, definitions of the terms were included in the first part of the questionnaire. Questions about body scanning focused on the awareness of scanners, process choice and process details for scanning.

Subjects were recruited from the universities in Izmir, Turkey. The questionnaire was sent to the university students and the academics in two different universities without considering the gender differences. Two groups were created for evaluation, first with the students and second with the academics. The reason of choosing these groups was the fact that students would reflect the general manner of younger people between 18-30 years old and academics would represent a group of older people over age 30 . The questionnaire reached approximately 200 students and 150 academics from different engineering departments. A sample group of 99 academics and 123 students were taken into consideration for evaluation. The results were analyzed statistically to find out the general perspective. Survey results were evaluated with SPSS 17.0 for Windows. Percentage values were found out and Chi-square test was applied.

\subsection{Scanning the second sample group formed with male participants}

The second data set consisted of a small sample group of 18-33 year old, 32 undergraduate male students from a German university. Subjects were recruited in the university by announcements and social networks. This part of the survey has been taken into consideration to provide a comparison based on gender. The questionnaire aimed to examine their reactions and the tendency to the process after actually being body scanned.

Participants were measured, both by traditional hand measurement method and by body scanning. Human Solutions Vitus Smart XXL 3D body scanner was used for this process. All participants were scanned with the standard posture in their underwear, without shoes, glasses or jewellery. For the measurement extraction of the scanner software, standard posture was a necessity. Participants were positioned in the scanning booth in the standard posture to capture as complete a body scan as possible, with feet apart and arms held at their sides but away from the body.

Following the scanning process, participants were measured by traditional anthropometric method by using a tape measure. Of the total 150 measurements obtained from the scanner, 29 were prioritized to be taken with a tape measure, which are the key interests from the clothing-technology viewpoint. Landmarks were defined (usually by feeling the bones beneath the skin) and were used to identify the measurements. The waist level was identified with a tape. Measurements were taken in a prespecified sequence and were recorded on pre-designed form.

Having completed the measurement taking process in both methods, participants viewed their body scan image on the computer monitor in different side views and in rotating positions. Participants then completed a questionnaire about their comfort level with all the measurement taking process, opinions of viewing their scans on the computer screen, their preference of measuring methods and the measuring process. The questionnaire was realized by personal communications for each participant and recorded on the sheets collaboratively. Finally the participants were offered to receive their measurements in a list and their images from the body scanner per e-mail. 


\subsection{Forming two groups from different nationalities}

The survey within this section was intended as a comparison between two different cultures and two different measuring methods. Two groups of sample sets were created for measurement taking. 1835 year old, female target group was defined for the research. Subjects were recruited in the universities by announcements and social networks.

Subjects in the first group were chosen in a German university. 80 female participants joined the process and were measured by Human Solutions Vitus Smart XXL body scanner. Same procedures were followed for scanning as the previous sample group.

Subjects in the second group were recruited in four different Turkish universities in Izmir. 90 participants joined this process and were measured by traditional anthropometric methods.

After measuring each subject, participants were asked to complete a questionnaire. The questionnaire was realized by personal communications for each participant and recorded on the sheets collaboratively. Same questions were directed to the students in both groups. Questions focused on their comfort level with the measurement taking process, opinions of viewing their scans on the computer screen, preferences of measuring methods and the measuring process. Finally the participants were offered to receive their measurements in a list or their images from the body scanner per e-mail

Results were evaluated statistically with SPSS 17.0 for Windows and were demonstrated differently for both groups. Percentage values were found out and Chi-square test was applied to compare the frequency of survey responses among the German and the Turkish group. Age differences were compared by independent T-test analyses.

\section{Results}

\subsection{Evaluating Turkish consumers' approach to scanning process}

Evaluating the results of 99 academics and 123 students, specific gender difference was not observed. Almost half of the total participants were female (\%52) and half were male $(\% 48)$.

- Among the first part of the questionnaire analysis, familiarity and awareness of customers to $3 \mathrm{D}$ body scanners was identified. For the question of whether the customers are aware of the use of 3D body scanners in clothing industry, only $27 \%$ of all claimed to be aware of the scanners.

- For customization parameters, design customization was seen to be the most important factor for students. However, fit customization was more important for academics showing the importance of fit mostly for older group.

- For the preference for body measuring process, only $14 \%$ of students preferred manual measurement taking, while for the academics this value was found out to be as $12 \%$. The interaction of $3 \mathrm{D}$ body scanners for customization was preferred more than manual measurement taking both for the students (\%55) and the academics (\%58). The allocations are shown in figure 1. 


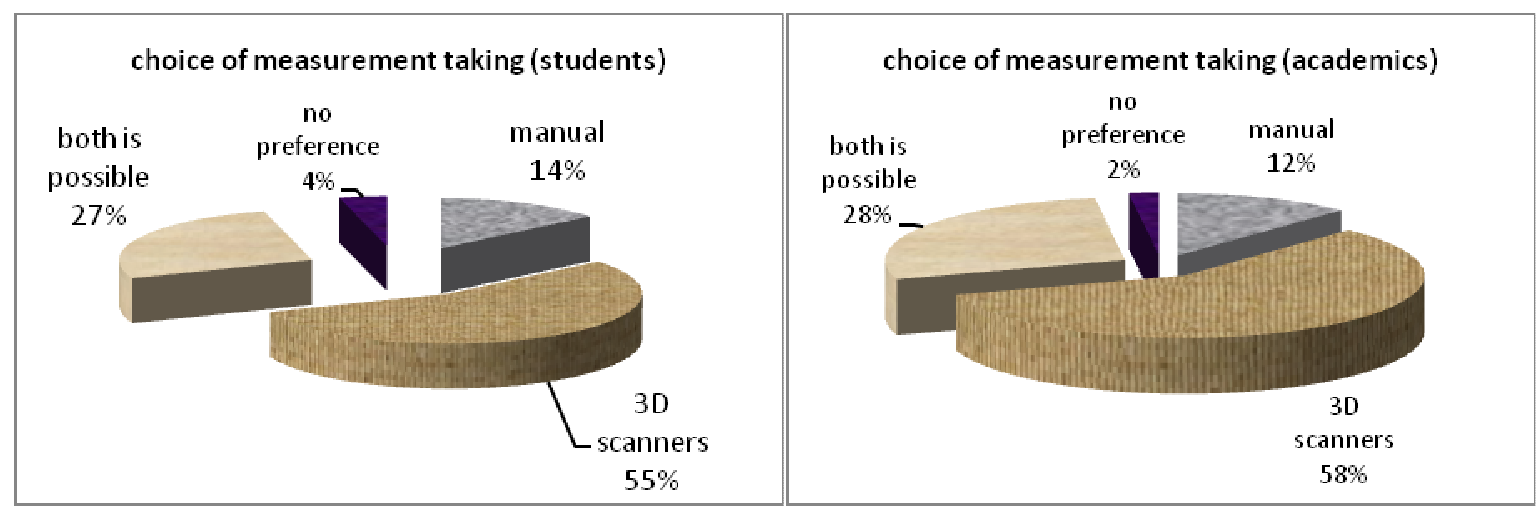

Fig.1. Results for the choice of measurement taking process.

Evaluations on body measuring process details included options as attire, assistance, process time and price increase for body scanner integrated and customized clothing production. Four different aspects of scanning process were examined as shown in Table 1.

Table 1. Preference for $3 D$ body scanning process

\begin{tabular}{|c|c|c|c|c|}
\hline \multicolumn{5}{|c|}{ 3D Body scanner measurement taking } \\
\hline & & Students (\%) & Academics (\%) & Total (\%) \\
\hline \multirow[t]{3}{*}{ Attire } & Underwear & 36 & 38 & 37 \\
\hline & Street clothes & 33 & 40 & 36 \\
\hline & Without clothes & 4 & 2 & 3 \\
\hline \multirow[t]{3}{*}{ Assistance } & By trained sales person & 60 & 55 & 58 \\
\hline & By themselves & 10 & 24 & 16 \\
\hline & A friend or person they know & 6 & 4 & 5 \\
\hline \multirow[t]{6}{*}{ Process time } & Up to $1 \mathrm{~min}$. & 25 & 47 & 34 \\
\hline & $1-3 \min$ & 20 & 26 & 23 \\
\hline & $3-6 \mathrm{~min}$. & 20 & 15 & 18 \\
\hline & $6-10 \mathrm{~min}$. & 17 & 7 & 13 \\
\hline & $10-15 \mathrm{~min}$. & 4 & 3 & 4 \\
\hline & $15-20 \mathrm{~min}$. & 9 & 1 & 5 \\
\hline \multirow[t]{4}{*}{ Price difference } & Up to $\% 10$ of normal price & 43 & 65 & 53 \\
\hline & Up to $\% 20$ of normal price & 29 & 26 & 30 \\
\hline & Up to $\% 50$ of normal price & 9 & 4 & 7 \\
\hline & Over $\% 50$ of normal price & 10 & 0 & 5 \\
\hline
\end{tabular}

Results with the sample data set showed that Turkish consumers are interested in body scanning even if they are not much informed about the use of scanners in clothing industry. Such a futuristic and practical approach took attention of the participants. Gender or age related differences were not observed to affect the results. Participants claimed that they would not pay much for such a process, which can be related with the economic conditions in the country. It might be necessary to increase consumers' confidence in a new technology and process so that they would be willing to spend more. 


\subsection{Evaluating the reactions of male participants}

In order to compare the reactions to scanning process on the gender base, the survey results of 32 male subjects' participation was evaluated.

- Having a sample group of students for the application of this process, most of whom are studying textile and clothing technology at the university, more than the half $(62 \%)$ of the participants claimed that they heard about the use of body scanner in the apparel industry.

- Considering the comfort aspect for the complete process of scanning and also with the flow of laser light, $44 \%$ of the participants claimed they felt comfortable (see figure 2). Participants were asked to evaluate the comfort within a scale of 1-5. Results showed that the considered comfort factor for most of the participants is within the upper half section of this 1 to 5 scale.

The aim of evaluating the comfort level during the laser light flow was to have an outcome for laser scanning technology. Only $9 \%$ of the participants claimed to feel disturbed, which was the 4th level in the comfort scale. The 5th level was not chosen by any of the participants.

However, the chosen group of students was recruited with posters and announcements advertising the study as an experiment by body scanning. Therefore participants were willing and interested to be scanned, which affected the results. The allocations would be much different with a group of different age categories and random consumers.

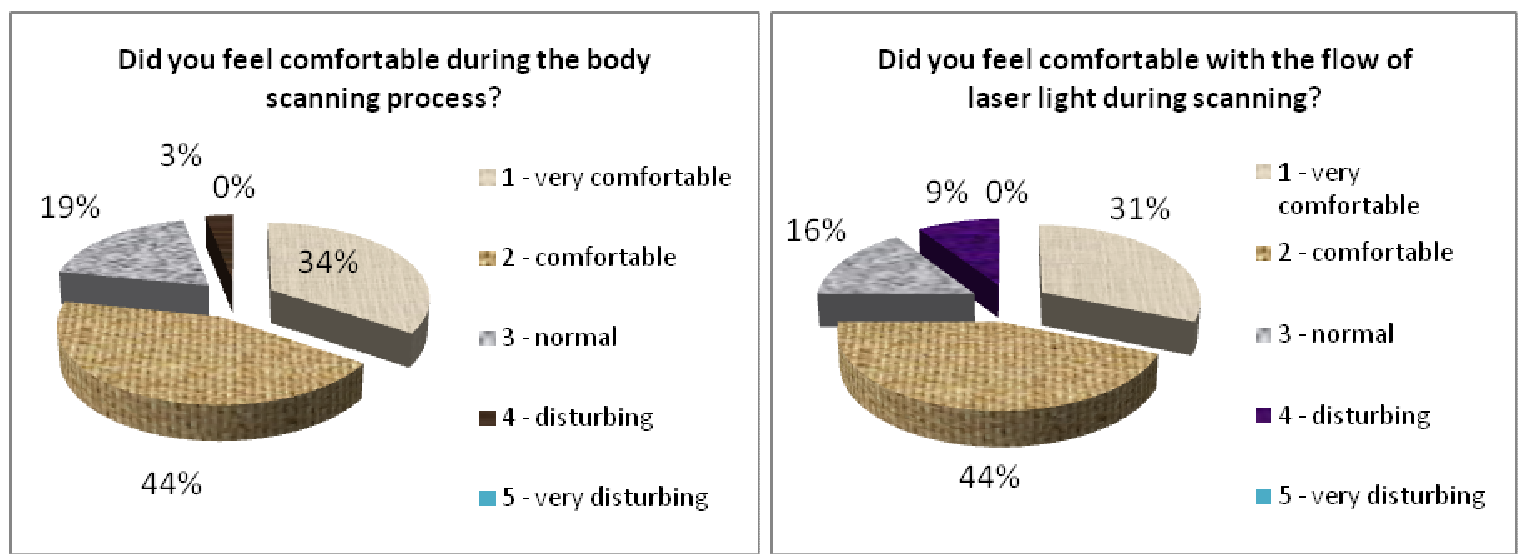

Fig.2. Results for the comfort level of scanning

- Participants were asked how comfortable they felt to view their scan on the computer screen. There were more deviations in the responses to this question. $28 \%$ of all participants claimed to feel very good to see their scan on the computer screen and $44 \%$ claimed that they felt good. $28 \%$ of the participants remarked a lower degree of comfort. None of the responses were matched with "4-disturbing" or "5-very disturbing" on the scale (see figure 3).

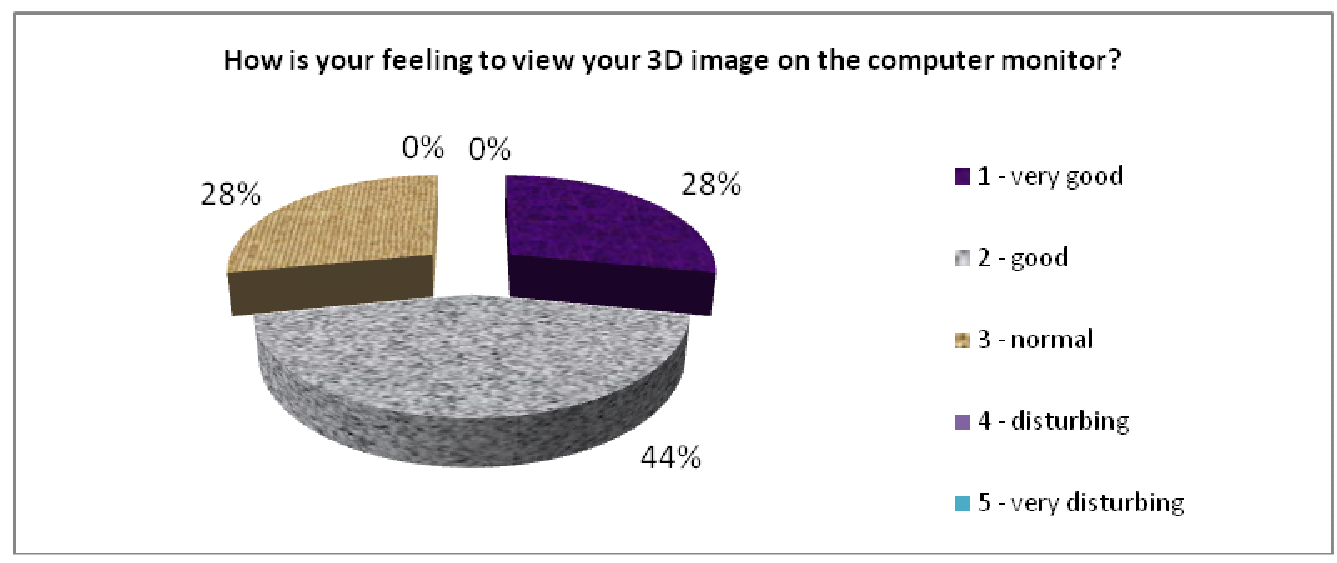

Fig.3. Results for the comfort level of viewing their 3D image on the monitor 
- When the participants were asked how they would prefer to be measured, $66 \%$ chose body scanning and only $6 \%$ said their first choice would be manual measurement. $28 \%$ claimed that they would prefer both of the methods either being scanned or being measured by a classical tape measure (see figure 4).

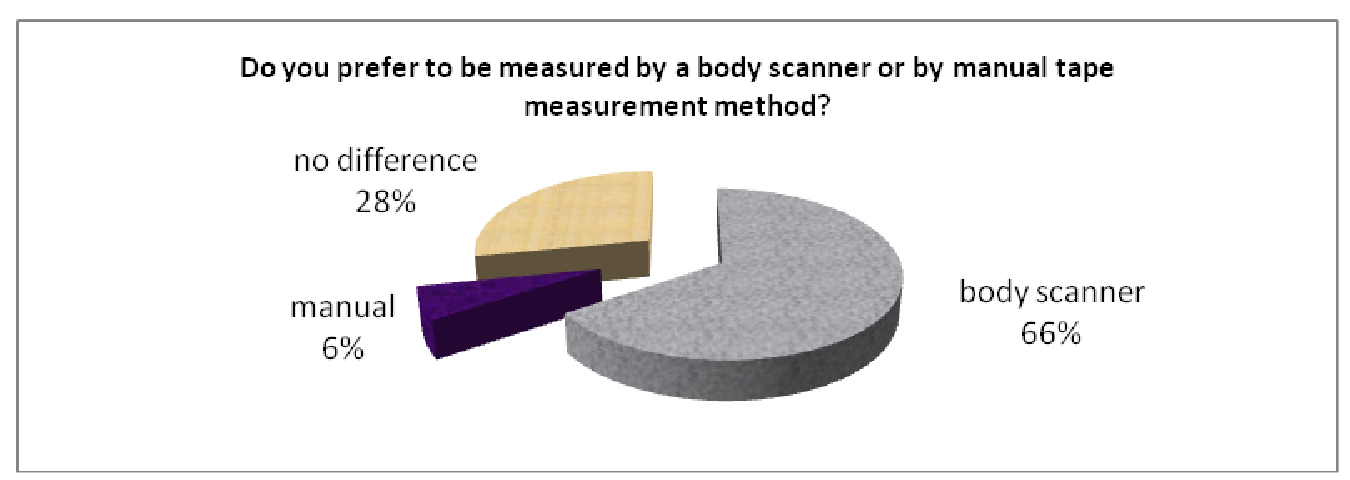

Fig.4. Results for the choice of measurement taking process.

- A big majority $(91 \%)$ of the participants were willing to participate in the body scanning process again.

- For the question about clothing, participants were asked to choose one or more options of clothing that they mostly would prefer to have for measurement taking. Almost $70 \%$ declared that it was comfortable with the underwear and they were not disturbed to be measured in their underwear for both of the methods. Only $20 \%$ off the participants stated that it would be better to be measured with body stocking and $11 \%$ with daily clothes.

- Mostly the participants with hard-to-fit bodies were willing to pay more for a customized product or go to a store for a fit trial more than once comparing to the participants who are well served by the ready-to-wear industry (see figure 5).

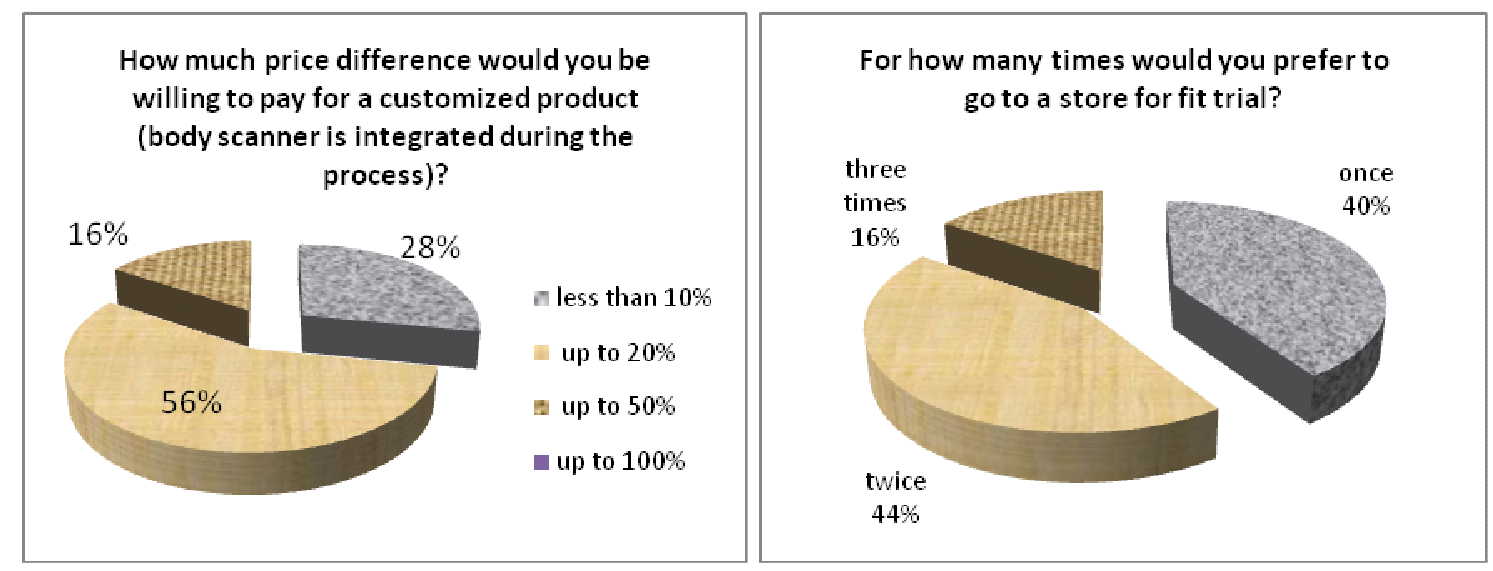

Fig.5.Degree of willingness to pay a price difference and willingness of a fit trial

The results of this part provided positive feedback for scanning and for some procedures of customization, as well as the potential interest in the technology of scanner. Positive ratings of comfort and willingness to be scanned were found to be at a high level. However, the sample group consisted of only a limited number of male students from a specific region of Germany. To obtain reliable results, the analysis should be conducted in a separate project based on the consumer behavior parameters and for extended groups. 


\subsection{Evaluating the reactions of female participants of two different nationalities}

The third part of the survey consisted of evaluations with two female groups with two different nationalities. For the age comparison, there was not a big difference in the age distribution of the groups. Independent T-test analyses were realized to compare the age differences. The difference between the two means was found to be statistically significant at the $5 \%$ level of significance $(p<0.001)$.

- Awareness of the use of a body scanner for measuring purposes was evaluated by comparing the groups (see figure 6). Based on Fisher's exact test, the relationship between the groups and the fact of having heard about the use of body scanner in apparel industry is significant at the $5 \%$ level of significance $(p<0.001)$.

If we only consider the first group, $66.3 \%$ of the participants claimed that they heard about the use of body scanner in apparel industry. This result was almost the same with the second sample group of male students, where both groups were chosen from German students.

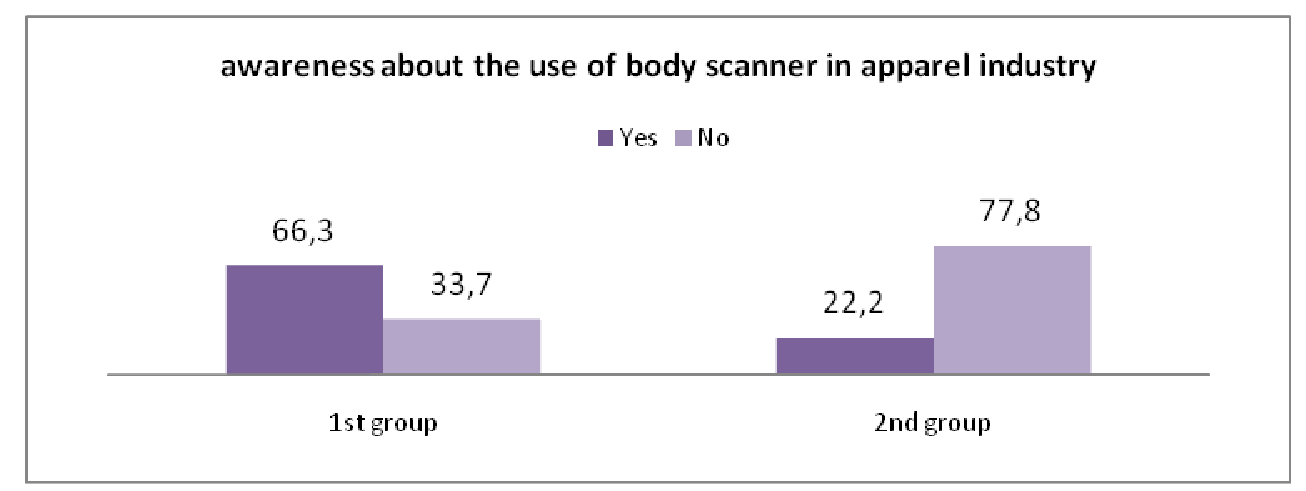

Fig.6. Comparison of the awareness about the use of body scanner in apparel industry

- Four questions about the process preference were directed to the participants in the first group, who were measured by the scanner. Results showed that the considered comfort factor for most of the participants is within the upper half section of this 1 to 5 scale. Comparing with the male subjects in the previous sample group, male participants declared to be more open and positive with the scanning process (see figure 7).

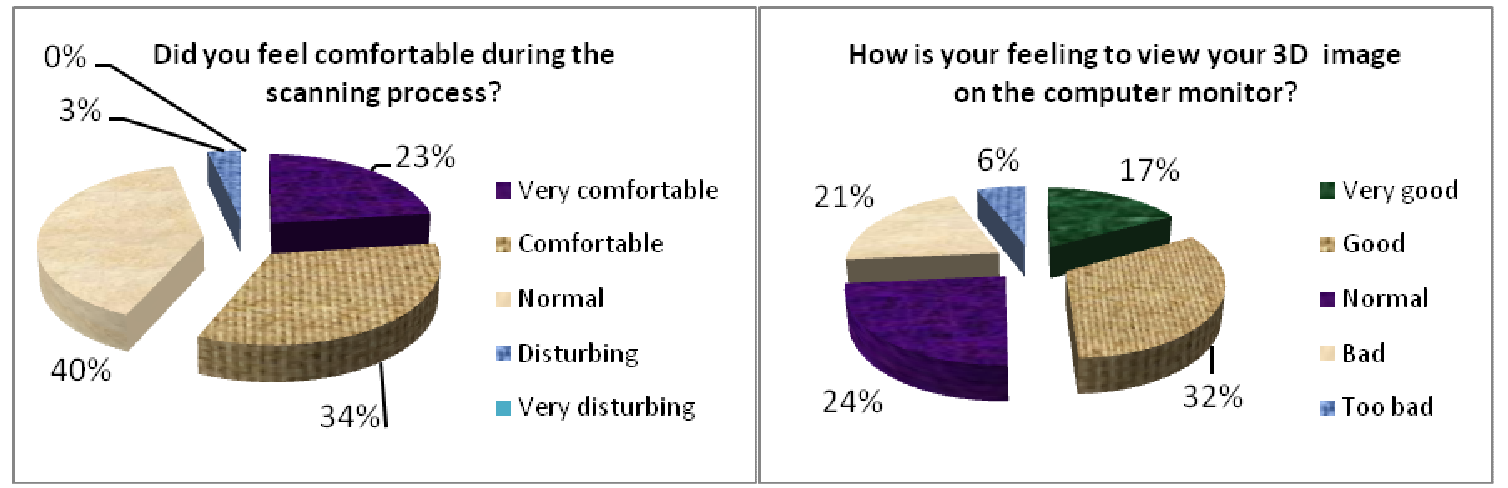

Fig.7. Results for the comfort level of scanning

- When the participants were asked how they would prefer to be measured, $69 \%$ chose body scanning and only $6 \%$ said their first choice would be manual measurement. $25 \%$ claimed that they would prefer both of the methods either being scanned or being measured by a classical tape measure. Results were very similar with the male group (see figure 8).

- Majority (\%73) of the participants was willing to participate in the body scanning process again (see figure 8). 


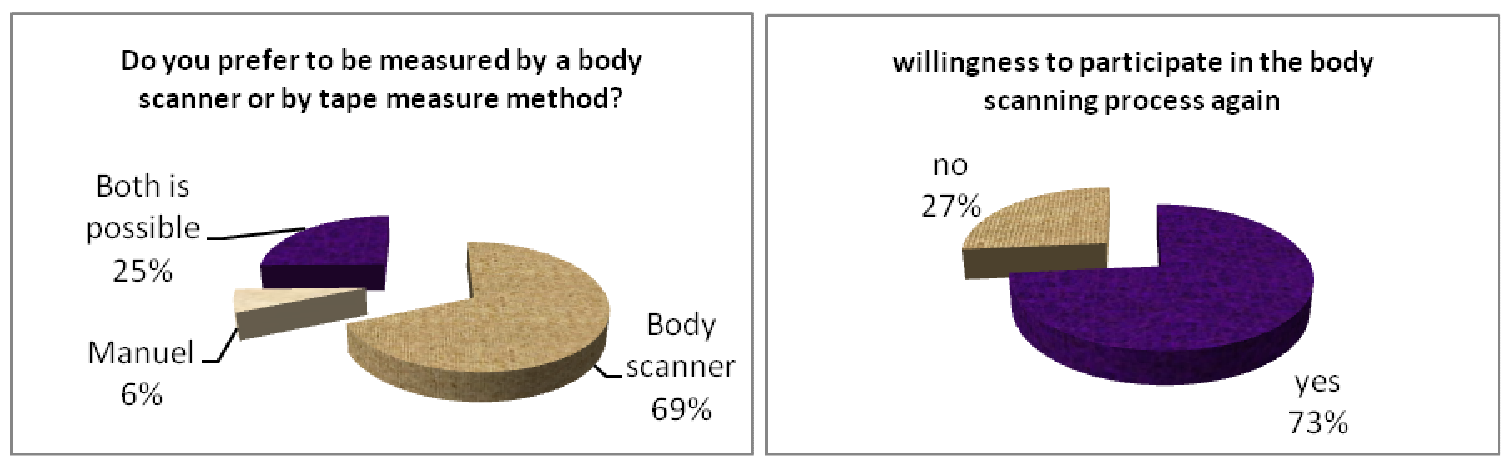

Fig.8. Results for the choice of measurement taking process and willingness to participate again

- Other evaluations were realized including both of the groups. For the question relating to the clothing part of the process, participants were asked to choose one or more options of clothing that they mostly would prefer for measurement taking process (see figure 9). Based on chi-square tests, the relationship between the groups and the clothing preferences is significant $(p<0.001)$ at the $5 \%$ level of significance. Underwear was the first preference for the first group, whereas; second group preferred body stocking or daily clothes. Apart from the cultural differences in both groups, differences in measuring methods were also a factor on this result. This result was a remarkable comparison among the groups.

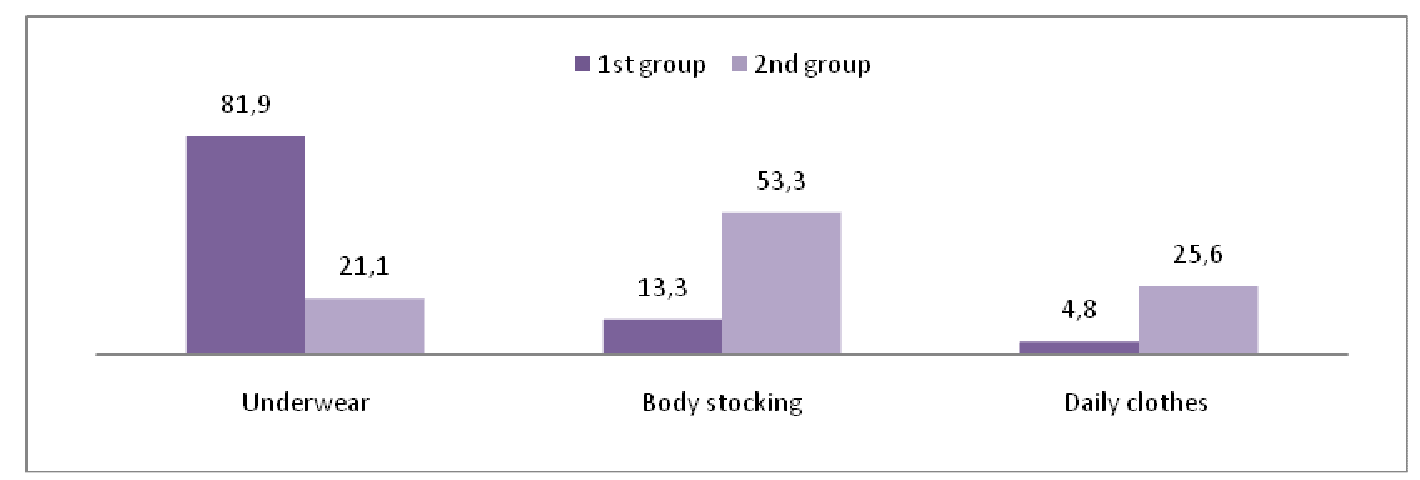

Fig.9. Clothing preferences during measurement taking

- Based on chi-square tests, the relationship between the groups and the willingness to pay a price difference for a customized product is significant at the $5 \%$ level of significance $(p=0.024)$. German participants were noticed to be ready for a price increase more than the Turkish group (see figure 10).

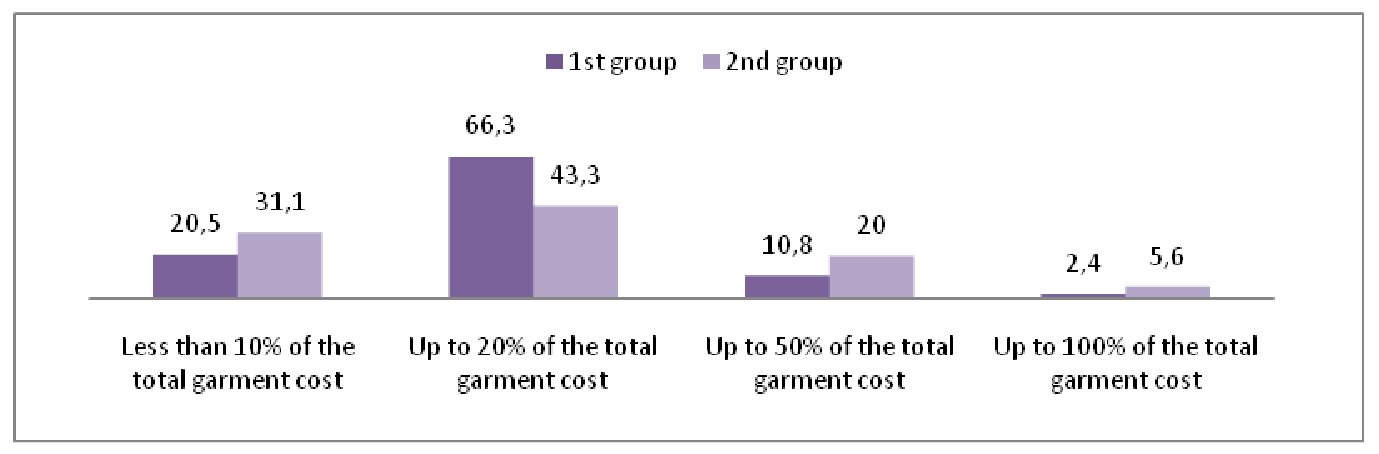

Fig.10. Degree of willingness to pay a price difference

- The relationship between the groups and the willingness to go to store for a fit trial is not significant based on chi-square tests $(p=0.510)$. 
Results obtained from the groups showed similarities to the other test groups in the previous sections, where most of the participants accepted to go to the store two times for fit trials (see figure 11).

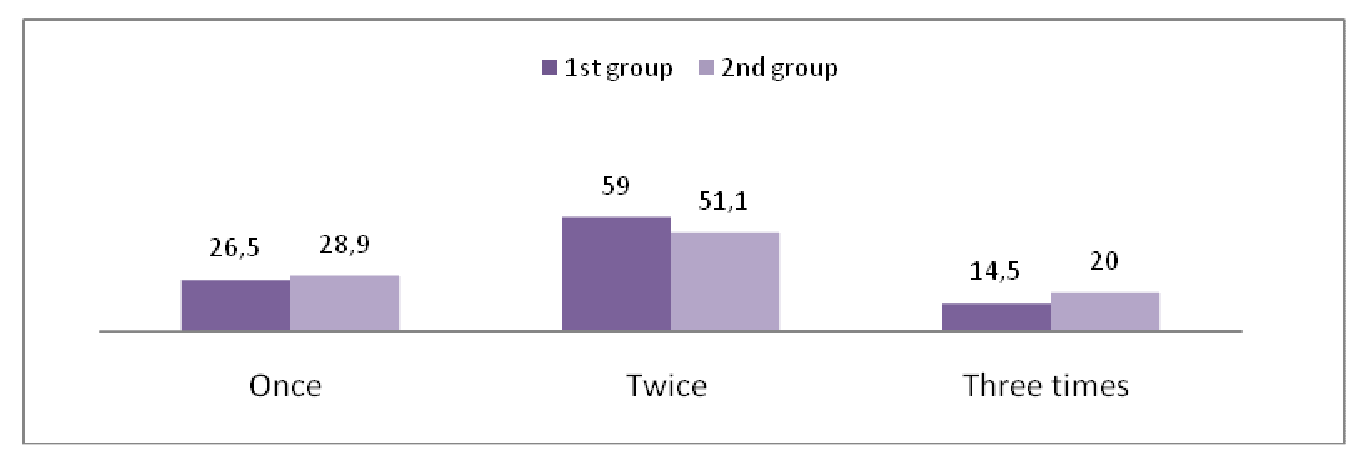

Fig.11. Degree of willingness to go to the store for a fit trial

The $\mathrm{X}^{2}$-test analyses were performed in this section to compare the frequency of responses between the first group and the second group for mutual questions. The results of the analyses say that there were statistically significant differences between the two groups. It can be predicted that this is a result of; firstly, the measurement techniques, where a different body measurement technique is used for the groups; and secondly, the cultural differences, since the participants in the groups were chosen from two different countries.

\section{Conclusion}

Within the content of this article, results of body scanning within different groups were analyzed. The outcomes confirm the consumer interest in the use of 3D body scanning for both the German and Turkish groups. For the Turkish consumers, since there isn't any commercial use of scanners in Turkey, this was a completely new topic. However, when the participants in the survey were informed about the scanner, they were interested to join the process and experience this high technology tool for measurement taking. After being informed, more than half of the participants in all sections of this survey declared that their first choice for measurement taking would be body scanners. Consumer concerns cluster around questions of price, privacy, time and the convenience of the system. The difficulty of implementing the use of such a new technology should bring to mind to familiarize the concept more to the consumers with marketing brochures or marketing campaigns. Especially in specific cultures, options such as clothing necessities, assistance, process time would create a difference from the consumer aspect. The location of scanning process should be arranged with the right space and right conditions.

In order to evaluate the results of consumer reactions after being scanned, it was only possible to scan German participants, where a scanner was available. Most of the participants expressed comfort with the scanning process and the flow of laser light for scanning as well as their positive comments to join the process again. Especially the sample group with male participants reacted more positively. Women were noticed to be significantly less comfortable with some aspects of body scanning.

Results of the study showed differences based on two groups considering different cultures. Therefore, consumer acceptance of a new technology should be covered within a specific cultural context. It was seen that Turkish consumers are open to new technologies, like body scanners; however, the process should be adapted to the society. Implementing a new process means investing on technology and marketing, therefore the analysis of the consumer and the detection of barriers in the local area should be considered in a wide-scale. Body scanners can be integrated in the processes for customization purposes. Another use of the scanners would be an anthropometrical survey. With the increasing population, Turkey can be a potential market for apparel brands. In this regard, a size survey would help for better fitting clothes and for identification of the population. Despite having trials for a Turkish size survey starting from the 1970s, a full-scale study has not been realized. With the development of scanners, the communities move forward in conducting anthropometric surveys by using the state-of-the-art scanning technologies. Many countries have been undertaking sizing surveys in recent years by using scanners to reduce the time and labour as well as increase the accuracy in the collection of anthropometric data. 
Turkey as a production country needs more customized solutions and technological investments for the maintenance and development of apparel and fashion industry. Besides this, a national size survey would carry importance considering the increasing population and consumer potential of the country. The survey in this study was important as a market survey; however, the limited number of participants was a limitation in the study. An extended survey would create more benefit to proceed further for possible applications such as a national size survey or made-to-measure developments.

It is expected that as the level of development increases, research or commercial based applications of scanning will also increase. Results of this study can provide a foundation for future research of the potential market in Turkey to develop a marketing strategy.

\section{References}

1. Fan, J., Yu, W. and Hunter, L., (2004): "Clothing appearance and fit: Science and technology", Woodhead Publishing Limited and CRC press LLC.

2. Loker, S., Cowie, L., Ashdown, S. and Lewis, V., (2004): "Female consumers' reactions to body scanning", Clothing and Textiles Research Journal, Vol. 22, No.4, pp. 151-160.

3. Lee, S., Kunz, G.I., Fiore, A.M. and Campbell, J.R., (2002): "Acceptance of mass customization of apparel: merchandising issues associated with preference for product, process and place." Clothing and Textiles Research Journal, Vol.20, No. 3, pp. 138-146.

4. Fiore, A.M., Lee, S., Kunz, G.I., Campbell, J.R., (2001): "Relationships between optimum stimulation level and willingness to use mass customization options", Journal of Fashion Marketing and Management, Vol. 5, No. 2, pp. $99-107$.

5. Loker, S., Ashdown, S., Cowie, L., Schoenfelder, K.A., (2004): "Consumer interest in commercial applications of body scan data", Journal of Textile and Apparel, Technology and Management, Vol.4, No. 1, pp.1-13.

6. Curran, L. (2009). "The EU clothing market in 2008 -opening the floodgates?", Journal of Fashion Marketing and Management, Vol.13, No.3, pp. 305-310.

7. Mete, F. (1999): "Bayan giyiminde serilendirme", Izmir TMMOB Tekstil Mühendisleri Odası Yayınları, Izmir.

8. Yesilpinar, S. (2006): "Giysi kalıpçıı̆ı 1", Tekstil, Hazır Giyim ve Boya Araştırma Uygulama Merkezi Yayınları, İzmir.

9. Yesilpinar, S. and Bulgun E., (2007): "Garment fitting problems of Turkish females towards mass customization", Proceedings of Autex 2007, Tampere University of Technology, Finland. 